This work is licensed under a Creative Commons Attribution 3.0 License.

\title{
Two new species of Dactylonotus Parent, 1934 (Diptera: Dolichopodidae) from South Africa and a key to Afrotropical species
}

\author{
Igor Ya. GRICHANOV \\ All-Russian Institute of Plant Protection, Podbelskogo 3, St.Petersburg, Pushkin, 196608, Russia. \\ E-mail: grichanov@mail.ru \\ urn:1sid:zoobank.org:author:5320AD3A-92D8-4820-8091-24802F8C8C06
}

\begin{abstract}
Two new species from South Africa, Dactylonotus nigricorpus sp. nov. and Dactylonotus tsitsikamma sp. nov., are described and illustrated. D. nigricorpus sp. nov. differs from all other species of the genus in the black body, the smaller size and the shorter antenna. D. tsitsikamma sp. nov. is peculiar in the genus in bearing a flag of long setae on the fifth segment of the fore tarsus. An identification key to 6 Afrotropical species of the genus is provided.
\end{abstract}

Key words. Diaphorinae, new species, identification key, Afrotropical Region.

Grichanov I.Ya. 2016. Two new species of Dactylonotus Parent, 1934 (Diptera: Dolichopodidae) from South Africa and a key to Afrotropical species. European Journal of Taxonomy 175: 1-9. http://dx.doi.org/10.5852/ $\underline{\text { eit.2016.175 }}$

\section{Introduction}

Based on recent results of a cladistics analysis, Capellari (2013) demonstrated the monophyly of the generic group including Anepsiomyia Bezzi, 1902, Argyra Macquart, 1834, Dactylonotus Parent, 1934, Somillus Brèthes, 1924 and Symbolia Becker, 1921 (composing the tribe Argyrini Negrobov, 1986, placed currently within the subfamily Diaphorinae, but deserving subfamily rank). The genus Dactylonotus is peculiar in its disjunctive distribution, with six species known from southern Africa and one species, D. formosus (Parent, 1933), inhabiting New Zealand (Grichanov 1998, 2000, this paper; Bickel 1999). The recent references dealing with this genus in the Afrotropical region include Grichanov (2011) and Grichanov et al. (2011a, 2011b). In this paper two new species from South Africa are described, and an identification key to Afrotropical species of Dactylonotus is presented.

\section{Material and methods}

The holotypes of the new species are housed at the National Museum, Bloemfontein, South Africa (BMSA). They were studied with a ZEISS Discovery V12 stereo microscope and photographed with an AxioCam MRc5 camera. Morphological terminology and abbreviations follow Cumming \& Wood (2009). Body length is measured from the base of the antenna to the tip of genital capsule. Wing length is measured from the base to the wing apex. Male genitalia were macerated in $10 \% \mathrm{KOH}$. The figures showing the hypopygium in lateral view (Figs 4, 10-12) are oriented as it appears on the intact specimen, 
with the morphologically ventral surface of the genitalia facing up, dorsal surface down, anterior end facing right and posterior end facing left.

\title{
Results
}

\author{
Class Hexapoda Blainville, 1816 \\ Order Diptera Linnaeus, 1758 \\ Suborder Brachycera Schiner, 1862 \\ Superfamily Empidoidea Latreille, 1804 \\ Epifamily Dolichopodoidae Latreille, 1809 \\ Family Dolichopodidae Latreille, 1809 \\ Subfamily Diaphorinae Schiner, 1864 \\ Tribe Argyrini Negrobov, 1986
}

Genus Dactylonotus Parent, 1934

Dactylonotus Parent, 1934: 136.

\section{Type species}

Dactylonotus grandicornis Parent, 1934 (by monotypy).

\section{Diagnosis}

The genus can be recognised by the finger-like projection or conus of the antennal pedicel, which overlaps the postpedicel dorsally in both sexes (Figs 2, 7); the postpedicel with distinct apex, with relatively short dorsal arista-like stylus, either median or subapical in position; the occiput convex or flat; male frons and face broad; legs with an anterior preapical seta on the mid and hind femora; the wing costa extending beyond tip of $\mathrm{R}_{4+5}$, ending at apex of vein $\mathrm{M}$; vein $\mathrm{M}$ unbroken (Figs 3, 8); and male sternite 8 with strong projecting setae (Figs 4,10 ).

\section{Remarks}

Two species of the genus were formerly associated with the genera Syntormon Loew, 1857 (Sympycninae), Neurigona Rondani, 1856 (Neurigoninae) and Tenuopus Curran, 1924 (Neurigoninae or genus incertae sedis), showing the uncertain position of Dactylonotus within the subfamily Diaphorinae. Such characters previously unknown for the genus as the black body (D. nigricorpus sp. nov.) and ornamented fore tarsus (D. tsitsikamma sp. nov.) confirm the close relation of Dactylonotus with Argyra and Somillus and their combination in an independent taxon of the subfamily rank.

\section{Dactylonotus nigricorpus sp. nov. urn:1sid:zoobank.org:act:6A263872-6460-45CF-8CDF-387C0D610111}

Figs $1-4,11$

\section{Diagnosis}

The new species is close to D. rudebecki Vanschuytbroeck, 1960 as described by Grichanov (1998) under the name $D$. meuffelsi, differing from the latter and all other species of the genus in the black body, smaller size, shorter antenna, the hypopygium morphology, the arista-like stylus apical, the mid femur without long setae, the simple tarsi with short claws and the small pulvilli.

\section{Etymology}

The species name is composed from Latin "niger" and "corpus" (black body). . 


\section{Type material}

\section{Holotype}

REPUBLIC OF SOUTH AFRICA: ${ }^{\lambda}$, Western Cape, Table Mountain N.P., Clovelly, sweeping grasses \& mature fynbos, $34^{\circ} 07.465$ S, $18^{\circ} 26.094$ E, 24 Oct. 2012, 64 m, A.H. Kirk-Spriggs (BMSA).

\section{Description}

Male (Figs 1-4, 11)

MeAsurements. Body length without antennae $3.8 \mathrm{~mm}$, antenna length $1.4 \mathrm{~mm}$, wing length $3.2 \mathrm{~mm}$, wing width $1.2 \mathrm{~mm}$.

HEAD. Frons small, black, grey pollinose, with medial trapezoid depression, slightly prominent around base of antennae; face densely whitish pollinose, weakly narrowed in upper part, with parallel sides in lower part, $2 \times$ as high as wide at clypeus; occiput flat, black, grey pollinose; one pair of long ocellar and short postvertical setae; no vertical setae; postocular setae black in upper part and white in middle and lower parts of head; eyes with short white hairs; antennae (Fig. 2) inserted at upper fifth of head, black, $2 \times$ longer than height of head; scape long, microscopically haired; pedicel with long, slightly widened at apex, dorso-lateral (inner view) process, covered by dorsal, lateral and ventral setulae; postpedicel

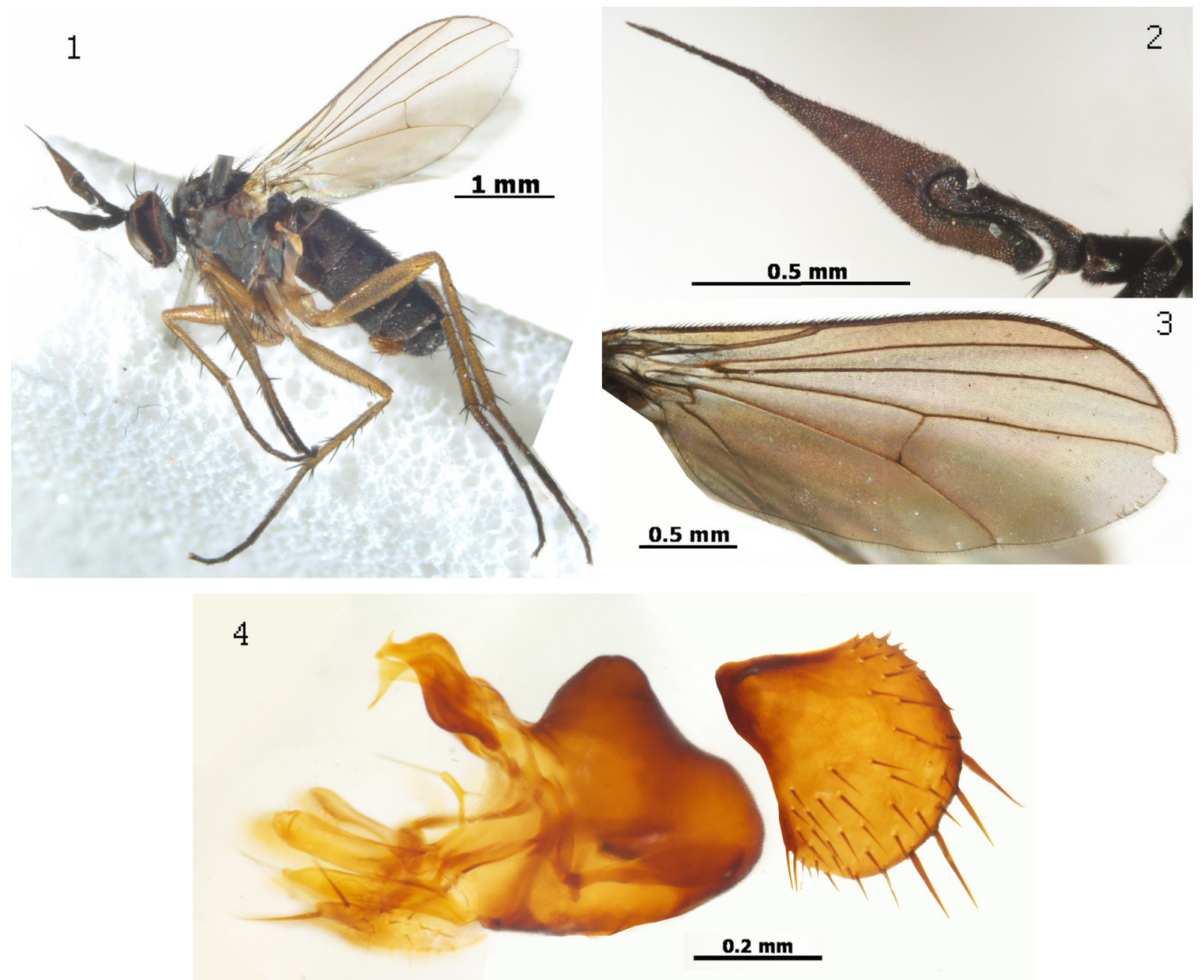

Figs 1-4. Dactylonotus nigricorpus sp. nov., §̂. 1. Habitus. 2. Antenna, inner lateral view. 3. Wing. 4. Hypopygium after maceration, left lateral view. 
very long, widest at apex of pedicel, with acute apex, $3 \times$ as long as high in middle, entirely covered by microscopic hairs; arista apical, with microscopic hairs. Length ratio of scape to pedicel to postpedicel (dorsal to ventral sides) to arista-like stylus ( $1^{\text {st }}$ and $2^{\text {nd }}$ segments) in $\mathrm{mm}, 0.27 / 0.40 / 0.49 / 0.74 / 0.05 / 0.32$. Palpus and proboscis short, black, with black hairs.

THORAX. Mostly black, with black bristles; mesonotum weakly pollinose; pleura densely grey pollinose; metanotum brownish below; propleuron with 2 strong black setae in lower part; 6 pairs of dorsocentral bristles decreasing in size anteriorly, with several scattered hairs on anterior slope; acrostichals biseriate, extending to $5^{\text {th }}$ pair of dorsocentrals; scutellum with two long strong bristles and two short fine lateral setae, $1 / 4$ as long as medians, dorsally bare.

LEGS. Including coxae yellow, with black bristles, tarsi brown-black from tip of basitarsus; fore coxa anteriorly with short black hairs and five or six black lateral and apical setae of various length in one row; mid coxa anteriorly with rather long black hairs and setae; mid and hind coxae with black bristle at base. Femora without long setae; mid and hind femora with one strong subapical anterior seta; fore tibia with 3 strong anterodorsal, 2 short posterodorsal, 3 short ventral setae; mid tibia with 3 strong anterodorsal, 1 small dorsal, 1 strong and 2 small posterodorsal, 1 anteroventral, 1-2 small posteroventral setae; hind tibia with 3 anterodorsal, 3 posterodorsal, $4-5$ short ventral setae; all tibiae with strong apical setae; all tarsi simple, with short claws and small pulvilli. Femur, tibia and tarsomere (from first to fifth) length ratio: fore leg: 65/75/38/22/16/11/10, mid leg: 88/102/51/27/21/12/12, hind leg: 95/120/39/39/28/17/12.

WING (Fig. 3). Ovate, fumous; veins brown; $R_{4+5}$ and $M_{1+2}$ slightly curved posteriad at apex; $M_{1+2}$ nearly straight; crossvein dm-cu straight; ratio of dm-cu to apical part of $\mathrm{CuA}_{1}$ (in $\mathrm{mm}$ ), 0.28/0.66; anal vein foldlike; anal angle obtuse; lower calypter yellow, with black cilia; halter yellow.

ABDOMEN. Mostly black, with black hairs and marginal setae; $6^{\text {th }}$ segment reduced; $7^{\text {th }}$ segment small, bare; $8^{\text {th }}$ segment with short hairs and row of strong setae; hypopygium (Figs 4, 11) black; epandrium subtriangular, strongly projected ventrally; hypandrium simple, broad, curved, with subapical spinelike process; phallus expanded at apex and biapicate; two epandrial setae positioned on distal side of epandrium, one of them (dorsal) pedunculate; epandrial lobe long, fingerlike, with rounded apex and short apical seta; surstylus yellow-brown, bilobate, with almost straight lobes, with several setae as figured; ventral lobe thinner than dorsal lobe, clavate; postgonite small, slightly curved ventrally; cercus short, yellow, with black setae.

Female

Unknown.

\section{Distribution}

South Africa (Western Cape).

Dactylonotus tsitsikamma sp. nov. urn:1sid:zoobank.org:act:9D497D9A-DFC2-4856-857A-86C75C373BB6

Figs 5-10, 12

\section{Diagnosis}

The new species is close to D. univittatus (Loew, 1858) as described by Grichanov (2000), differing in the presence of the posterior brush of long setae on the fifth segment of the fore tarsus, the brownish yellow hypopygium and the morphology of the hypopygial appendages. The arista-like stylus is middorsal; the fore coxa are with black hairs; the mid femur is without long hairs and setae. 


\section{Etymology}

The species is named after the Tsitsikamma National Park in South Africa, where the type material was collected.

\section{Type material}

\section{Holotype}

REPUBLIC OF SOUTH AFRICA: $\widehat{\jmath}$, [Eastern Cape,] Tsitsikamma N.P., below Sleepkloof, malaise trap, indigenous forest, $33^{\circ} 56.974$ S, $23^{\circ} 54.926$ E, 20-22 Jan. 2009, 64 m, A.H. Kirk-Spriggs \& S. Otto (BMSA).

\section{Description}

Male (Figs 5-10)

MeAsuRements. Body length without antennae $5.5 \mathrm{~mm}$, antenna length $1.6 \mathrm{~mm}$, wing length $5.0 \mathrm{~mm}$, wing width $1.7 \mathrm{~mm}$.

HEAD (somewhat shrunken). Frons as wide as high, black, grey pollinose, with medial rhomboid depression; face densely whitish pollinose, narrow; occiput flat, black, grey pollinose; one pair of long


Figs 5-10. Dactylonotus tsitsikamma sp. nov., ô. 5. Habitus. 6. Antenna, outer lateral view. 7. Antenna, inner lateral view. 8. Wing. 9. Apical segments $4-5$ of fore tarsus. 10. Hypopygium after maceration, left lateral view. 
ocellar and short postvertical setae; no vertical setae; postocular setae black in upper part and white in middle and lower parts of head; eyes with short white hairs; antennae (Figs 6-7) inserted at upper fourth of head, dirty-yellow, brownish dorsally and apically, $1.5 \times$ longer than height of head; scape long, bare; pedicel long, slightly widened at apex, dorso-lateral (inner view) process, covered by dorsal, lateral and ventral setulae; postpedicel very long, widest at apex of pedicel, with narrow rounded apex, $2.8 \times$ as long as high in middle, entirely covered by microscopic hairs; arista-like stylus middorsal, with short hairs. Length ratio of scape to pedicel to postpedicel (dorsal to ventral sides) to arista-like stylus ( $1^{\text {st }}$ and $2^{\text {nd }}$ segments) in mm, 0.33/0.38/0.40/0.73/0.43/0.60. Palpus and proboscis short, yellow, with black hairs.

THORAX. Mostly brownish yellow, with black bristles; mesonotum with broad median metallic blue violet stripe embracing area between $2^{\text {nd }}-6^{\text {th }}$ pairs of dorsocentrals; scutellum dorsally blue-violet with yellow margin; pleura with a black spot below calypter; thoracic pollination weak; proepisternum with 2 long brownish ventral setae and 4 yellow hairs above; 6 pairs of dorsocentral bristles decreasing in size anteriorly, with several scattered hairs on anterior slope; acrostichals biseriate, extending to $5^{\text {th }}$ pair of dorsocentrals; scutellum with two long strong bristles and two short fine lateral setae, $1 / 4$ as long as medians, dorsally bare.

Legs. Including coxae yellow, with black bristles, apical segments of all tarsi brownish; fore coxa anteriorly with short black hairs and row of six black lateral and apical setae of various length; mid coxa anteriorly with rather long black hairs and setae; mid and hind coxae with black bristle at base; hind coxa with additional small seta below middle; femora without long setae; mid and hind femora each with one strong preapical anterior bristle; fore tibia with 3 strong anterodorsal, 2 short posterodorsal setae; mid tibia with 3 strong anterodorsal, 1 small dorsal, 3 strong posterodorsal setae; hind tibia with 3 anterodorsal, 5 posterodorsal, $4-5$ short ventral setae; all tibiae with strong apical setae; $4^{\text {th }}$ and $5^{\text {th }}$ segments of fore tarsus slightly swollen; $5^{\text {th }}$ segment (Fig. 9) of same tarsus with posterior brush of flattened setae, as long as $5^{\text {th }}$ segment, with slightly enlarged claws and pulvilli; mid and hind tarsi simple, with short claws and small pulvilli. Femur, tibia and tarsomere (from first to fifth) length ratio (in $\mathrm{mm}$ ): fore leg: 1.65/1.63/1.02/0.41/0.28/0.2/0.22, mid leg: $1.82 / 2.05 / 1.14 / 0.55 / 0.43 / 0.28 / 0.19$, hind leg: 2.27/2.5/0.7/0.71/0.42/0.27/0.19.

WING (Fig. 8). Ovate, almost hyaline; veins brown; $\mathrm{R}_{2+3}$ and $\mathrm{R}_{4+5}$ slightly curved posteriad at apex; $\mathrm{M}_{1+2}$ nearly straight; crossvein dm-cu straight; ratio of dm-cu to apical part of $\mathrm{CuA}_{1}$ (in $\mathrm{mm}$ ) $0.36 / 0.92$; anal vein foldlike; anal angle obtuse; lower calypter yellow, with black cilia; halter yellow.
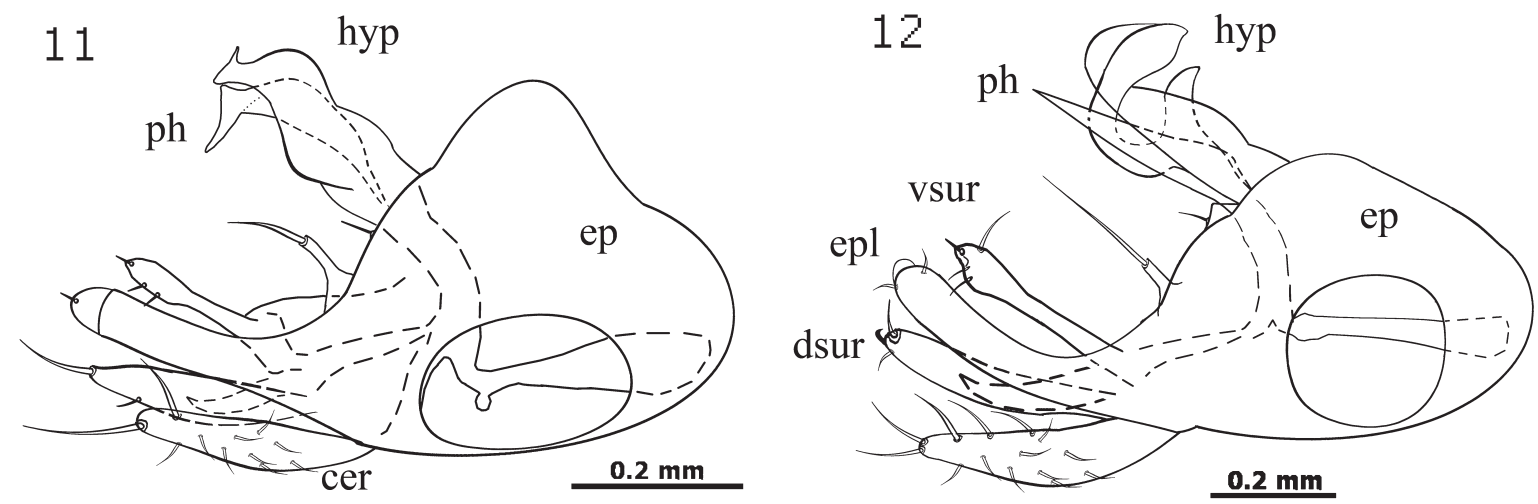

Figs 11-12. Hypopygium, left lateral view. 11. Dactylonotus nigricorpus sp. nov. 12. Dactylonotus tsitsikamma sp. nov. Abbreviations: $\mathrm{cer}=$ cercus; $\mathrm{ep}=$ epandrium; $\mathrm{epl}=$ epandrial lobe; hyp = hypandrium; $\mathrm{ph}=$ phallus; dsur, vsur $=$ dorsal and ventral lobes of surstylus. 
ABDomen. Mostly yellow, with black hairs and marginal setae; $1^{\text {st }}$ segment brownish anteriorly; $2^{\text {nd }}$ segment with brown T-shaped spot dorsally; $3^{\text {rd }}-5^{\text {th }}$ segments each with triangular dark-brown spot dorsally; $6^{\text {th }}$ segment reduced, brown; $7^{\text {th }}$ segment small, bare; $8^{\text {th }}$ segment and epandrium mostly dirty yellow, partly brown, $8^{\text {th }}$ segment with short hairs and row of strong setae; hypopygium (Figs 10,12 ) yellow-brown; epandrium ovate; hypandrium broad, with 2 large ventral projections; phallus pointed at apex; two epandrial setae positioned on distal side of epandrium, one of them (dorsal) pedunculate; epandrial lobe long, fingerlike, with rounded apex and 2 short apical setae; surstylus yellow-brown, bilobate, with almost straight lobes, with several apical setae as figured; ventral lobe thinner than dorsal lobe, clavate; postgonite thick, slightly curved ventrally; cercus short, yellow, with black setae.

\section{Female}

Unknown.

\section{Distribution}

South Africa (Eastern Cape).

\section{Key to the Afrotropical species of Dactylonotus (males)}

1 Thorax and abdomen almost entirely black (Fig. 1); postpedicel 3 times longer than high; aristalike stylus apical (Fig. 2); body $3.8 \mathrm{~mm}$............................ nigricorpus sp. nov.

- Thorax and abdomen mostly yellow; postpedicel various in length; arista-like stylus subapical or



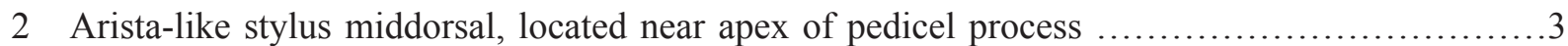

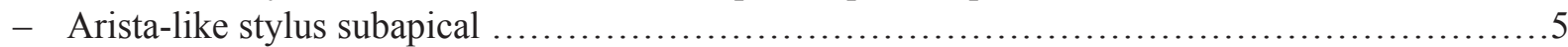

3 Fore coxa with yellow-brown bristles; mid femur with two ventral rows of black setae in basal half, half as long as femur diameter; body $5 \mathrm{~mm}$................. D. grandicornis Parent, 1934

- Fore coxa with black bristles; mid femur without long setae ..............................

4 Fifth segment of fore tarsus without posterior brush of long setae; hypopygium brown-black; body $4.6-5.3 \mathrm{~mm}$.................................................. univittatus (Loew, 1858)

- Fifth segment of fore tarsus with posterior brush of long setae (Fig. 9); hypopygium (Fig. 10) brownish yellow; body $5.5 \mathrm{~mm}$.

D. tsitsikamma sp. nov.

5 Fore tarsus with enlarged pulvilli; postpedicel 3 times longer than high; arista-like stylus as long as postpedicel; body $4 \mathrm{~mm}$......................................... frater Parent, 1939

- Tarsal pulvilli normal; postpedicel 4.5 times longer than high; arista-like stylus half as long as postpedicel; body $4.7 \mathrm{~mm}$ D. rudebecki Vanschuytbroeck, 1960

\section{Discussion}

Unfortunately, for each of the newly described species only one male was found despite intensive collecting with malaise trap and sweeping. Because the secondary sexual characters of these species (including the structure of their genitalia) are unique, their identification will not be problematic in the future. Dactylonotus nigricorpus sp. nov. is the only species with a black body, whereas the other species have mainly yellow bodies. D. tsitsikamma sp. nov. is remarkable in the genus in bearing a flag of long setae on the fifth segment of the fore tarsus. I think their descriptions are important due to our incomplete knowledge of the southern African dolichopodids and our poor understanding of the diaphorine genera. The two new species and $D$. frater seem to be extremely rare in nature, all known by a single male only. Summarising my work with the genus over the last 20 years, I could find 319 specimens of D. grandicornis, 37 specimens of D. univittatus and 9 specimens of $D$. rudebecki in the collections of 
dozens European and African museums. Thus, classical patterns of relative species abundance (e.g., McGill et al. 2007) are here confirmed. Expanded knowledge of the genus will probably be essential to improve our understanding of the phylogenetic relations among diaphorine flies of the world.

\section{Acknowledgements}

The author is sincerely grateful to Dr. Ashley H. Kirk-Spriggs (Bloemfontein, South Africa) for his kindness in providing specimens for study. The editorial team of the EJT and anonymous reviewers kindly commented on earlier drafts of the manuscript. The work was partly supported by the Russian Foundation for Basic Research grant N 14-04-00264-a.

\section{References}

Bickel D. 1999. Australian Sympycninae II: Syntormon Loew and Nothorhaphium, gen. nov., with a treatment of the Western Pacific fauna, and notes on the subfamily Rhaphiinae and Dactylonotus Parent (Diptera: Dolichopodidae). Invertebrate Taxonomy 13: 179-206.

Capellari R.S. 2013. Phylogeny of the Diaphorinae (Diptera: Dolichopodidae). In: Klass K.-D. (main organizer) 6th Dresden Meeting on Insect Phylogeny, September 27-29, 2013. Abstracts - Poster Presentations: 56.

Cumming J.M. \& Wood D.M. 2009. Chapter 2. Adult morphology and terminology. In: Brown B.V., Borkent A., Cumming J.M., Wood D.M., Woodley N.E. \& Zumbado M.A. (eds) Manual of Central American Diptera, Volume 1: 9-50. NRC Research Press, Ottawa.

Grichanov I.Ya. 1998. A new species of Dactylonotus Parent (Diptera: Dolichopodidae) from South Africa. International Journal of Dipterological Research 9 (1): 27-29.

Grichanov I.Ya. 2000. Afrotropical Neurigoninae and notes on the diaphorine genus Dactylonotus Parent (Diptera: Dolichopodidae). Belgian Journal of Entomology 2: 257-271.

Grichanov I.Ya 2011. An illustrated synopsis and keys to Afrotropical genera of the epifamily Dolichopodoidae (Diptera: Empidoidea). Priamus Serial Publication of the Centre for Entomological Studies Ankara Supplement 24: 1-99.

Grichanov I.Ya., Mostovski M.B. \& Muller B. 2011a. New records of Afrotropical Dolichopodidae (Diptera) from the collection of Natal Museum (1). International Journal of Dipterological Research 22 (1): 3-9.

Grichanov I.Ya., Mostovski M.B. \& Muller B. 2011b. New records of Afrotropical Dolichopodidae (Diptera) from the Collection of Natal Museum (2). International Journal of Dipterological Research 22 (2): 81-98.

McGill B.J., Etienne R.S., Gray J.S., Alonso D., Anderson M.J., Benecha H.K., Dornelas M., Enquist B.J., Green J.L., He F., Hurlbert A.H., Magurran A.E., Marquet P.A., Maurer B.A., Ostling A., Soykan C.U., Ugland K.I. \& White E.P. 2007. Species abundance distributions: moving beyond single prediction theories to integration within an ecological framework. Ecology Letters 10 (10): 995-1015. http://dx.doi. org/10.1111/j.1461-0248.2007.01094.x

Parent O. 1934. Additions à la faune éthiopienne (Diptères: Dolichopodidés). Bulletin de la Société entomologique d'Égypte 18: 112-138.

Manuscript received: 9 October 2015

Manuscript accepted: 12 January 2016 
Published on: 16 February 2016

Topic editor: Koen Martens

Desk editor: Kristiaan Hoedemakers

Printed versions of all papers are also deposited in the libraries of the institutes that are members of the EJT consortium: Muséum national d'Histoire naturelle, Paris, France; Botanic Garden Meise, Belgium; Royal Museum for Central Africa, Tervuren, Belgium; Natural History Museum, London, United Kingdom; Royal Belgian Institute of Natural Sciences, Brussels, Belgium; Natural History Museum of Denmark, Copenhagen, Denmark. 